\title{
Editorial
}

\section{Dyspepsia: A Common Medical Condition}

\author{
Received: April 20, 2018 Accepted: April 30, 2017 \\ doi: http://dx.doi.org/10.3329/jemc.v8i2.36727
}

Dyspepsia is a common medical condition. It affects $20-45 \%$ of general adult population. ${ }^{1,2}$ The term 'dyspepsia' was derived from the Greek term 'dyspeptos' which literally means 'difficult to digest'. 'Indigestion' is the non-medical term for dyspepsia. Despite continuous effort of several international working teams the meaning and definition of dyspepsia continues to challenge clinical investigators. To emphasize the site of origin of dyspepsia from upper GI tract, more recently, dyspepsia is used to describe 'pain or discomfort centered in the upper abdomen. ${ }^{3}$ Dyspepsia is used to describe a constellation of symptoms arising from upper abdomen, such as upper abdominal 'discomfort', 'pain', bloating, upper abdominal fullness, burning, flatulence, satiation, nausea, vomiting, heart-burn, regurgitation, frequent burping (belching) and anorexia. However, the symptoms of heartburn, acid regurgitation, and belching were excluded from the definition of dyspepsia in Rome (I \& II) reports because of their relation to gastroesophageal reflux disease (GERD) and aerophagia. According to Rome III committee dyspeptic pain must be located more precisely in the epigastric region, and other key symptoms (early satiety and fullness) should be meal related (http://www.romecriteria.org). GERD symptoms are included under the term of dyspepsia by the Canadian Dyspepsia Working Group (CANDYS) ${ }^{3}$ and by the UK National Institute for Health and Care Excellence (NICE). The American Gastroenterological Association's (AGA) technical review for the evaluation of dyspepsia ${ }^{4}$ excludes GERD symptoms from dyspepsia. No specific duration of symptoms is required by CANDYS, whereas NICE requires 4 weeks and ROME IV (http://www.romecriteria.org) requires 12 weeks in the last year to qualify as dyspepsia.

Dyspepsia can be classified in the following ways. Uninvestigated dyspepsia is a condition in which characteristic upper GI symptoms have not been recently investigated by UGI endoscopy. ${ }^{3,4}$ Functional dyspepsia (sometimes called non-ulcer dyspepsia) refers to a condition where no cause for the dyspepsia could be found out following UGI endoscopy.,

Dyspeptic symptoms may have organic basis (peptic ulcer disease, gastritis and occult acid reflux, gastric carcinoma, metabolic disorders, lactose intolerance, cholelithiasis etc.), but the vast majority (70-80\%) of cases of dyspeptic symptoms are functional in nature (functional dyspepsia). ${ }^{4-6}$ Despite their important medical and economic implications, ${ }^{6,7}$ the pathophysiologic mechanisms involved in functional gastrointestinal symptoms are still poorly understood.

Dyspepsia is also common in Bangladesh. A recent study including endoscopy in 90 dyspeptic subjects showed normal finding in $22.2 \%$ cases, gastritis in $30.0 \%$, duodenitis in $10.0 \%$, carcinoma in $31.1 \%$ and reflux disease (GERD) in $2.2 \%$ cases. $^{8}$

Although most people affected by dyspepsia do not seek medical care for their symptoms, the burden of illness with respect to quality of life and economic consequences of dyspepsia is considerable. ${ }^{9-11} \mathrm{~A}$ large cross-sectional survey in the UK suggests that dyspepsia may be costing society approximately $£ 1$ billion ( $\$ 1.46$ billion) annually. ${ }^{10}$ Similar estimates were also reported from United States for the costs of diagnosis and management of dyspepsia. ${ }^{11}$

Symptoms are not a good predictor of the underlying endoscopic findings. Most dyspeptic patients have no significant abnormalities at endoscopy. Zagari et $\mathrm{al}^{12}$ shows a high prevalence of esophagitis among patients with predominant reflux symptoms, but peptic ulcer disease is also frequently found in this population, particularly in $\mathrm{H}$. pylori infected subjects. Investigation of dyspepsia is costly. Alarm symptoms are often mentioned in guidelines as a method to decide who should receive early endoscopy as no suitable alternative is currently available. Recent studies show the limitations of alarm symptoms in dyspeptic patients in predicting a serious underlying abnormality. ${ }^{12,13}$ In the study by Zagari et $\mathrm{al}^{12}$ in patients with alarm symptoms or signs, there were no endoscopic abnormalities in $65 \%$ of patients, $9 \%$ had neoplasia, $14 \%$ had esophagitis and $8 \%$ had benign peptic ulcer. ${ }^{12}$

The age threshold for early endoscopy varies in different countries, 45-55 years of age is generally 
recommended in Western countries whereas earlier age has been proposed in Asia and Eastern Europe. ${ }^{3}$ A recent study showed that the costs of endoscopy in a dyspeptic population to detect serious underlying conditions were very large and probably unsustainable at a time of limited resources. ${ }^{4}$

Dyspeptic patients more than 55 years old, or those with alarm features (bleeding, anemia, early satiety, unexplained weight loss $>10 \%$ of body weight, progressive dysphagia, odynophagia, persistent vomiting, a family history of gastrointestinal cancer, previous esophagogastric malignancy, previous documented peptic ulcer, lymphadenopathy, or an abdominal mass) should undergo prompt endoscopy to rule out serious underlying upper GI disorder. In the absence of alarm features and in patients aged 55 years or younger, the clinician may adopt two approximately equivalent management strategies: (i) test and treat for $\mathrm{H}$. pylori using a validated noninvasive test and if symptoms persist despite $\mathrm{H}$. pylori eradication, a trial of acid suppression or (ii) an empiric trial of acid suppression with a proton pump inhibitor (PPI) for 4-8 wks. The test-and-treat option is preferable in populations with a moderate to high prevalence of $H$. pylori infection $(\geq 10 \%)$ whereas the empirical PPI strategy is preferable in low prevalence areas. Some anxious patients may need endoscopy for reassurance. Repeat endoscopy usually is not recommended in case of a firm diagnosis of functional dyspepsia unless completely new symptoms or alarm features develop. Repeat endoscopy is not costeffective. If a patient is unwilling to accept a probable diagnosis and has concerns about malignancy, early investigation with endoscopy may be appropriate. ${ }^{14}$

No consensus is available regarding on how, in whom and when to test for H. pylori infection in dyspepsia. ${ }^{15,16}$ The treatment of $\mathrm{H}$ pylori-associated dyspepsia in the absence of ulcers is also controversial. ${ }^{15,16} \mathrm{~A}$ recent systematic review suggests that treating non-ulcer dyspepsia with an $\mathrm{H}$. pylori regimen is reasonable and cost-effective. ${ }^{17}$ Other investigators argued that like endoscopy, anti-H. pylori treatment has cost and feasibility issues. ${ }^{18}$ Several investigators have stressed on the potential adverse outcomes associated with the widespread use of antimicrobials, such as alteration of the normal flora and increasing antimircrobial resistance. ${ }^{18}$

According to the American Gastroenterological Association, the most reasonable strategy for the management of patients who present with dyspepsia is non-invasive testing for $\mathrm{H}$. pylori infection followed by eradication of the organism if the test is positive. A cost-utility study in a primary care setting reached the same conclusions. ${ }^{19}$ Supporting data included the comparative cost-effectiveness of this approach and its lower potential for antibiotic resistance.

The situation in Bangladesh is not clear-cut. H. pylori prevalence in the general population is more than $80 \%{ }^{20}$ and $\mathrm{H}$. pylori prevalence among dyspeptic patients is around $67 \%{ }^{21}$. Still there is no effective regimen available against $\mathrm{H}$. pylori and re-infection rate is also high following eradication..$^{22}$ Bismuth and furazolidone-based anti-H pylori therapies (highly effective) are not commercially available in our country. We have no national guidelines for managing dyspeptic patients. Serology-based investigations are unable to differentiate past $\mathrm{H}$. pylori infections from current infections. Non-invasive specific tests for $\mathrm{H}$. pylori have not been yet validated in our country.

In the absence of national guideline we can follow Asia-Pacific guideline for management of dyspepsia. In Asia-Pacific guideline prompt endoscopy is recommended for patients with alarm features. In patients without alarm features, treatment for 2-4 weeks with an empirical anti-secretory or prokinetic agent, followed by investigation using non-invasive Helicobacter pylori testing and treatment for patients who do not respond or relapse, is recommended. ${ }^{23}$

So, in conclusion dyspepsia is a common medical condition with important medical and economic implications. Despite diverse causes of dyspepsia, a vast majority of cases are due to functional disorder which needs counseling and symptomatic treatment. Investigation of dyspepsia is costly and unpleasant to the patients. Therefore, judicious use of endoscopy is important for diagnosis of dyspepsia. Empiric treatment with anti-secretory drugs or with prokinetics in the absence of alarm features in young patients is of paramount importance in the treatment of dyspepsia. In refractory or relapsed cases, patients should be tested non-invasively for $\mathrm{H}$ pylori and should be treated with locally effective regimen.

\section{Irin Perveen}

Professor, Department of Gastroenterology

Enam Medical College \& Hospital, Savar, Dhaka

Email: irinperveen@yahoo.com 


\section{References}

1. Tougas G, Chen Y, Hwang P, Liu MM, Eggelston A. Prevalence and impact of upper gastrointestinal symptoms in the Canadian population: findings from the DIGEST study. Am J Gastroenterol 1999; 94: 2845-2854.

2. Van Zanten SJ, Flook N, Chiba N, Armstrong D, Barkun A, Thomson A et al. An evidence based approach to the management of uninvestigated dyspepsia in the era of Helicobacter pylori. CMAJ 2000; 162 (Suppl 12): S3-23.

3. Dickerson LM, King DE. Evaluation and management of nonulcer dyspepsia. Am Fam Physician 2004; 70: $107-114$.

4. Talley NJ, Silverstein MD, Agreus L, Nyren O, Sonnenberg A, Holtmann G. AGA technical review: evaluation of dyspepsia. American Gastroenterological Association. Gastroenterology 1998; 114: 582-595.

5. Locke GR. $3^{\text {rd }}$ prevalence, incidence and natural history of dyspepsia and functional dyspepsia. Baillieres Cline Gastroenterol 1998: 12: 435-442.

6. Talley NJ, Stanghellini V, heading RC, Koch KL, Malagelada JR, Tytgat GN. Functional gastroduodenal disorder. Gut 1999: 45(suppl 2): 1137-1142.

7. Talley NJ. Vakil N. The practice parameters committee of the American College of Gastroenterology. Guidelines for the management of dyspepsia. Am J Gastroenterol 2005: 100: 2324-2337.

8. Shafiullah ABM, Bhuiyan MMR, Masud H, Roy PK. Endoscopic findings in a district private hospital of Bangladesh. Bangladesh J Medicine 2009; 20: 17-19.

9. Talley NJ, Weaver AL, Zinsmeister AR. Impact of functional dyspepsia on quality of life. Dig Dis Sci 1995; 40: 584-589.

10. Moayyedi P, Mason J. Clinical and economic consequences of dyspepsia in the community. Gut 2002; 50: iv10-iv12.

11. Lacy BE, Weiser KT, Kennedy AT, Crowell MD, Talley NJ. Functional dyspepsia: the economic impact to patients. Aliment Pharmacol Ther 2013; 38(2): 170-177.

12. Zagari RM, Law GR, Fuccio L, Pozzato P, Forman D, Bazzoli F. Dyspeptic symptoms and endoscopic findings in the community: the Loiano-Monghidoro study. Am J Gastroenterol. 2010; 105(3): 565-571.
13. Vakil N, Moayyedi P, Fennerty MB. Limited value of alarm features in the diagnosis of upper gastrointestinal malignancy: systematic review and meta-analysis. Gastroenterology 2006; 131: 390-401.

14. Talley NJ. Non-ulcer dyspepsia: current approaches to diagnosis and management. Am Fam Physician 1993; 47: $1407-1416$.

15. Lambert JR. The role of Helicobacter pylori in nonulcer dyspepsia. A debate for. Gastroenterol Clin North Am 1993; 22: 141-151.

16. Talley NJ. The role of Helicobacter pylori in non-ulcer dyspepsia. A debate against. Gastroenterol Clin North Am 1993; 22: 153-167.

17. Moayyedi P, Soo S, Deeks J, Forman D, Mason J, Innes $\mathrm{M}$ et al. Systematic review and economic evaluation of Helicobacter pylori eradication treatment for nonulcer dyspepsia. Dyspepsia Review Group. BMJ 2000; 321(7262): 659-664.

18. Rabeneck L, Graham DY. Helicobacter pylori: when to test, when to treat. Ann Intern Med 1997; 126: 315-316.

19. Ebell MH, Warbasse L, Brenner C. Evaluation of the dyspeptic patient: a cost-utility study. J Fam pract 1997; 44: 545-555.

20. Ahmad MM, Rahman M, Rumi AK, Islam S, Huq F, Chowdhury MF et al. Prevalence of Helicobacter pylori in asymptomatic population-a pilot serological study in Bangladesh. J Epidemiol 1997; 7(4): 251-254.

21. Habib AM, Alam MJ, Rudra B, Quader MA, AlForkan M. Analysis of Helicobacter pylori prevalence in Chittagong, Bangladesh, based on PCR and CLO Test. Microbiol Insights 2016; 9: 47-50.

22. Hildebrand P, Bardhan P, Rossi L, Parvin S, Rahman A, Arefin MS et al. Recrudescence and reinfection with Helicobacter pylori after eradication therapy in Bangladeshi adults. Gastroenterology 2001; 121: 792-798.

23. Talley NJ, Lam SK, Goh KL, Fock KM. Management guidelines for uninvestigated and functional dyspepsia in the Asia-Pacific region: First Asian Pacific Working Party on Functional Dyspepsia. J Gastroenterol Hepatol 1998; 13(4): 335-353. 